\title{
Fluorinated Organic Porous Materials
}

\author{
Zhenglin Zhang \\ Ognjen Š. Miljanić* (iD \\ Department of Chemistry, University of Houston, \\ 112 Fleming Building, Houston TX 77204-5003, USA \\ miljanic@uh.edu
}

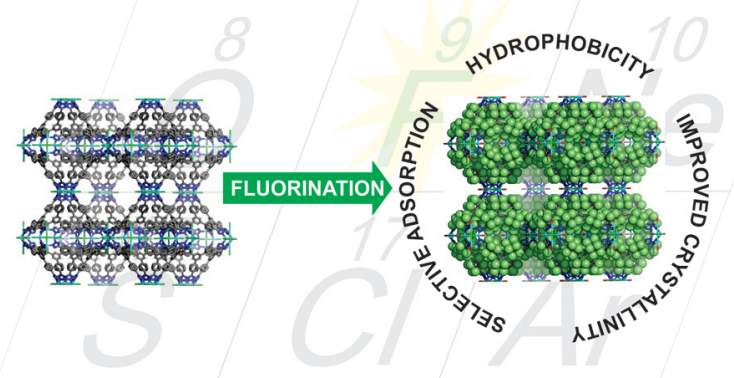

Received: 20.06.2019

Accepted after revision: 24.07.2019

DOI: 10.1055/s-0039-1698431; Art ID: om-19-0004-rev

License terms: (C)

(c) 2019. The Author(s). This is an open access article published by Thieme under the terms of the Creative Commons Attribution-NonDerivative-NonCommercial-License, permitting copying and reproduction so long as the original work is given appropriate credit. Contents may not be used for commercial purposes, or adapted, remixed, transformed or built upon. (https://creativecommons.org/licenses/by-nc-nd/4.0/)

Abstract Fluorine is in many aspects unique among the elements, and its incorporation into organic molecules can dramatically change their physical and chemical properties. This minireview will survey the existing classes of fluorinated porous materials, with a particular focus on all-organic porous materials. We will highlight our work on the preparation and study of metal-organic frameworks and porous molecular crystals derived from extensively fluorinated rigid aromatic pyrazoles and tetrazoles. Where possible, comparisons between fluorinated and nonfluorinated materials will be made.

Key words fluorinated molecules, porous materials, molecular crystals, macrocycles

\section{Introduction}

Fluorine is the ninth element in the periodic table. It has one stable and NMR-active isotope $\left({ }^{19} \mathrm{~F}\right)$, the highest electronegativity (3.98 on the Pauling scale), and the third-shortest van der Waals radius of $1.47 \AA$, longer only than those of $\mathrm{H}(1.10 \AA)$ and $\mathrm{He}(1.40 \AA){ }^{1}$ The $\mathrm{C}-\mathrm{F}$ bonds are among the strongest in organic chemistry, with bond dissociation energies as high as $130 \mathrm{kcal} \mathrm{mol}^{-1}$, and an average length of $1.35 \AA$ A. Introduction of fluorine into the structures of organic compounds, and especially the formal replacement of $\mathrm{C}-\mathrm{H}$ with $\mathrm{C}-\mathrm{F}$ bonds, has profound effects on the structures and reactivities of said compounds. Since fluorine is only a bit larger than hydrogen, such substitution changes the sterics minimally, but the electronics profoundly. This feature led to an explosion of interest in the incorporation of fluorine into pharmaceuticals, ${ }^{2}$ and the

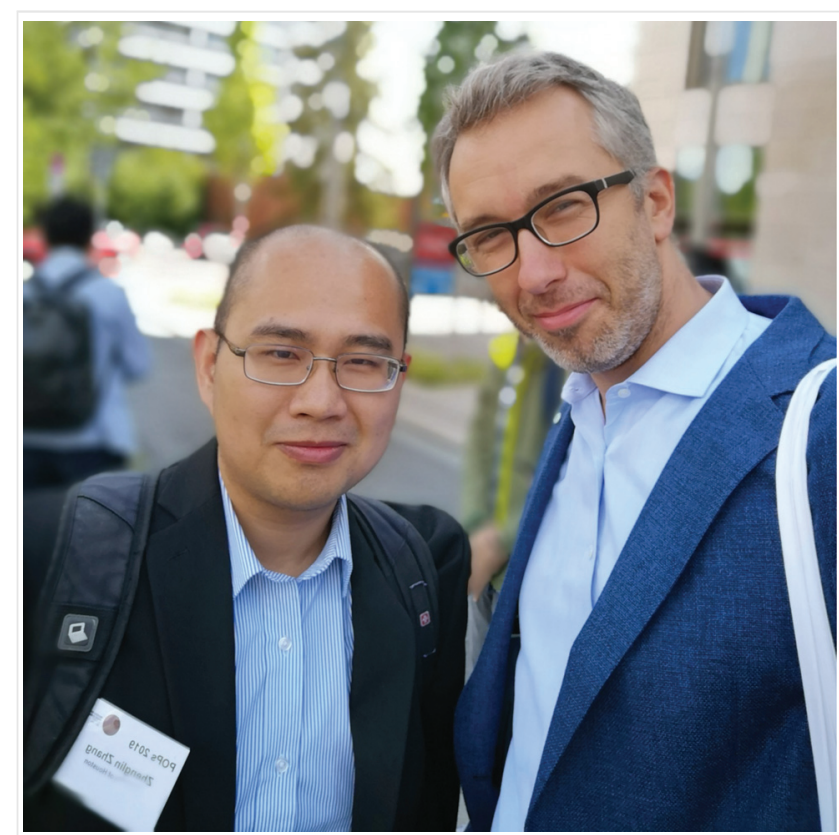

Zhenglin Zhang (left) is from Ganzhou in China. He obtained his B.Sc. in Applied Chemistry (2011) from Liaoning Shihua University and a M.Sc. in Chemical Engineering and Technology (2014) from Beijing University of Technology. He has been working in Miljanic's group at the University of Houston since October 2015. Currently, he is a $\mathrm{Ph}$.D. candidate with research interests in fluorescent and porous materials.

Ognjen Š. Miljanic (right) was born in Belgrade, then Yugoslavia, in 1978. He holds a Diploma from the University of Belgrade (2000) and a Ph.D. from the University of California at Berkeley (2005), where he worked with Prof. K. Peter C. Vollhardt. Following a postdoctoral stay in Prof. J. Fraser Stoddart's group at UCLA (2005-2008), Ognjen joined the University of Houston (UH) in 2008 as an Assistant Professor. He was promoted to Professor in 2019. He held visiting professorships at New York University Abu Dhabi and Ruprecht-KarlsUniversität in Heidelberg. Among other distinctions, he is the recipient of UH Teaching \& Research Excellence, NSF CAREER, and Cottrell Scholar awards, and a Fellow of the Royal Society of Chemistry. 
creation of numerous modern methods for the functionalization of $\mathrm{C}-\mathrm{H}$ bonds with fluorine atoms or fluorinecontaining functional groups. ${ }^{3,4}$ Materials chemistry has also been exploring fluorination as a method of modulating chemical and thermal stability, as well as physical properties, in polymers and other classes of materials. ${ }^{5,6}$

In this minireview, we will summarize the recent advances in the preparation and utilization of fluorinated porous materials. Our text will be divided into four sections, discussing the effects of fluorination on the structures and properties of (1) metal-organic frameworks (MOFs), (2) covalent organic frameworks (COFs) and porous organic polymers (POPs), (3) extrinsically porous molecular crystals (PMCs), and (4) intrinsically porous molecular cages. These classes of materials are distinguished by the connections between their building blocks, which are also responsible for the assembly of porous solid-state structures. In MOFs, they are metal-ligand bonds; in crystalline COFs and amorphous POPs, they are covalent bonds between organic fragments; in PMCs, weak noncovalent interactions. Finally, porous molecular cages are constructed from covalently connected elements that create a pore within a molecule. Cages then bring this pore with them into the solidstate structure, in which noncovalent interactions between the individual cages can vary in strength and directionality. We will not strive for a comprehensive treatment of fluorinated MOFs in this short account. Instead, we will focus on offering a personal perspective and-to the extent primary literature permits-the comparison of properties of fluorinated porous materials with those of their nonfluorinated counterparts. The reader is referred to two reviews on fluorinated MOFs, ${ }^{7,8}$ as well as to numerous other general reviews of MOFs, ${ }^{9-12}$ COFs, ${ }^{13-16}$ and PMCs. ${ }^{17-22}$

\section{Metal-Organic Frameworks}

Fluorinated MOFs have been the subject of study since the mid-2000s. Early work in this area focused on the hydrogen adsorption behavior in porous materials with exposed fluorine atoms; ${ }^{23,24}$ since then, other intriguing properties of this class of MOFs have been identified. Particularly notable were the studies of Omary and coworkers, who have shown that MOFs based on fluorinated triazolate ligands can be effective in hydrocarbon adsorption, while adsorbing essentially no water even at $90 \%$ relative humidity. ${ }^{25,26}$ This combination of properties was proposed as useful in the cleanup of oil spills and hydrocarbon storage, and it suggested that the preparation and study of fluorinated MOFs are very warranted. At the same time, true structureproperty studies of fluorinated MOFs were severely restricted by the paucity of the appropriately functionalized large fluorinated ligands.

Our entry into this area was inspired by the desire to expand the range of organic building blocks for use in MOF chemistry. To do so, we initiated a collaboration with the group of Prof. Olafs Daugulis at the University of Houston. Initially, a series of linear highly fluorinated carboxylic acids and tetrazoles was prepared using a combination of $\mathrm{Cu}$ - and $\mathrm{Pd}-$ catalyzed chemistry. Our first joint publication ${ }^{27}$ reported several MOFs derived from these ligands and two main conclusions: (1) MOFs prepared from fluorinated linkers were superhydrophobic, but (2) were also thermally and hydrolytically less stable than their nonfluorinated counterparts. This lowered stability, especially in the case of carboxylate-based fluorinated MOFs, could tentatively be explained by $(a)$ easier decarboxylation, which would result in the creation of aromatic anions stabilized by the electron-withdrawing fluorine atoms, and (b) lowered basicity of fluorinated carboxylates, which made them weaker ligands for the metals.

By switching from linear to trigonal geometry and through the replacement of carboxylate ligands with tetrazolates, more porous and more robust fluorinated MOFs could be prepared. A material named MOFF-5 was prepared from trigonal linker $\mathbf{1}$ by reaction with $\mathrm{CuCl}_{2} \cdot \mathrm{H}_{2} \mathrm{O}$ (Figure 1 ). ${ }^{28}$ Its stability was sufficient to allow full characterization and revealed a surface area of $\sim 2400 \mathrm{~m}^{2} \mathrm{~g}^{-1}$-the

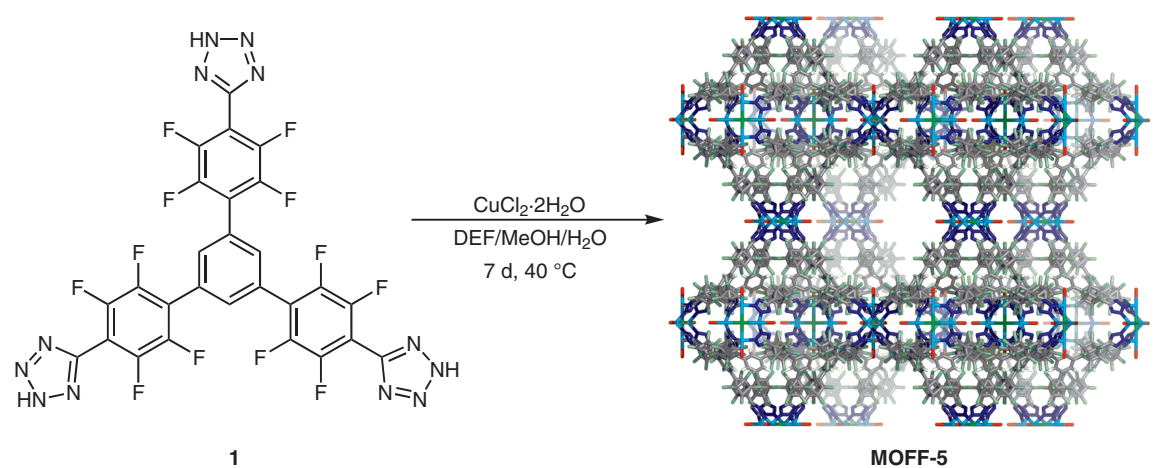

Figure 1 Synthesis of a fluorinated metal-organic framework MOFF-5. Crystal structure of MOFF-5 shown on the right, with element colors: C-gray, O-red, N-blue, F-lime, Cl-green, $\mathrm{Cu}-$ cyan. 
highest among the fluorinated MOFs at the time. This material has shown high gravimetric adsorption capacities for a variety of fluorinated guests, including fluorocarbons, hydrofluorocarbons (HFCs), and chlorofluorocarbons, reaching as much as $225 \mathrm{wt} \%$ for perfluorohexane. These results have broader relevance in the improvement of efficiency of air conditioners, ${ }^{29}$ and the lowering of greenhouse emissions coming from HFCs, which are hundreds of times more potent greenhouse gases than carbon dioxide.

However, the stability of the tetrazolate-based framework was still not perfect: after five or six sorption/desorption cycles it would start losing its crystallinity and eventually completely decompose. Our attempt to solve this problem led us into the field of PMCs, as will be described below.

\section{Covalent Organic Frameworks and Porous Organic Polymers}

Examples of fluorinated COFs in the literature are relatively rare, but several important side-by-side comparisons have been made. Sun and coworkers prepared three isostructural imine-based COFs from tetraphenylbenzene tetraaldehydes which were disubstituted with hydrogen, methoxy, or fluoro groups. ${ }^{30}$ Their structures were solved using continuous rotation electron diffraction and were found to be five-fold interpenetrated and very similar to each other. The fluorinated material had a much higher affinity for $\mathrm{CO}_{2}$ than the nonfluorinated framework, as well as a higher (50:1) IAST (ideal adsorbed solution theory) selectivity for $\mathrm{CO}_{2}$ over $\mathrm{N}_{2}$. In three separate studies, imine- ${ }^{31,32}$ and azine-linked ${ }^{33}$ COFs (example in Figure 2, left) have been shown to organize better and lead to more crystalline materials if fluorine atoms are included into the structures of their monomers. Evidence of this improved crystallinity in fluorinated materials was found in the higher resolution of their powder X-ray diffraction patterns and the clear observation of crystallites by scanning electron microscopy. In the case of azine-linked COFs, an explanation for the observed improvements in both crystallinity and porosity was that the fluorinated layers aligned well with nonfluorinated ones through aromatic stacking, thus fixing the interlayer arrangement in place and increasing order in the materials. ${ }^{34}$ Nevertheless, single-crystalline fluorinated COFs have not been reported yet.

Wen and colleagues have shown that perfluorinated covalent triazine frameworks (CTFs, example in Figure 2, top right $)^{35}$ serve as excellent electrocatalysts for the conversion of $\mathrm{CO}_{2}$ into $\mathrm{CH}_{4}{ }^{36}$ Postsynthetic introduction of sulfur functional groups into related CTFs could be accomplished through an $S_{N} A r$ reaction on the fluoro substituents; the resulting sulfur-containing CTFs were of interest in lithiumsulfur batteries. ${ }^{37-39}$ Fluorinated CTFs have also been utilized for selective and moisture-tolerant capture of $\mathrm{CO}_{2},{ }^{40,41}$ again with high IAST selectivity over the adsorption of nitrogen. ${ }^{42}$ A very recent study has identified a CTF based on fluorinated aryl ethers which showed a $\mathrm{CO}_{2}$ uptake capacity of 6.58 $\mathrm{mmol} \mathrm{g}^{-1}$ (29.0 wt\%) at $273 \mathrm{~K}$ and 1 bar-among the highest values reported for POPs and related materials to date. ${ }^{43}$ This high sorption capacity was attributed to the to the presence of

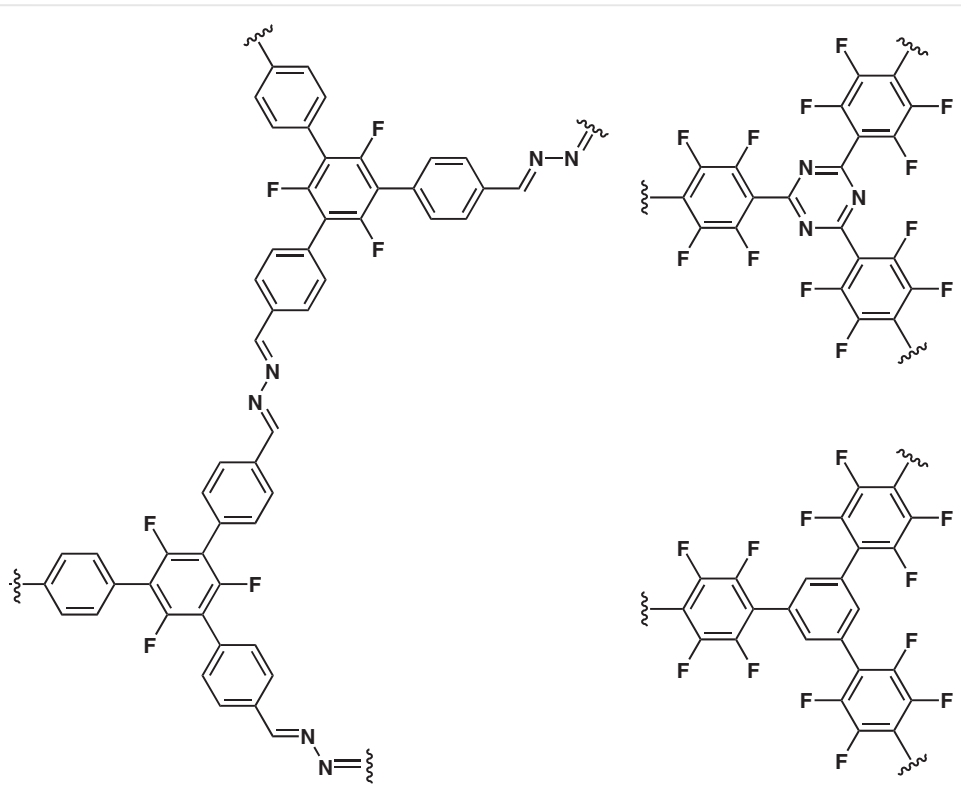

Figure 2 Examples of structural motifs found in fluorinated COFs (left), CTFs (top right), and POPs (bottom right). 
ultra-micropores of $0.6-0.7 \mathrm{~nm}$ in size and strong electrostatic interactions with the residual fluorine atoms within the framework. Molecular simulation suggested that CTF with F content of $\sim 4.8 \mathrm{wt} \%$ and pore size distribution around $\sim 0.7 \mathrm{~nm}$ should have the highest $\mathrm{CO}_{2}$ uptake capacity, in agreement with the previous studies. ${ }^{44}$ Studies of mechanical stiffness of CTFs substituted with trifluoromethyl groups revealed behavior similar to glass polymers and zeolitic imidazolate frameworks. ${ }^{45}$

Qi and coworkers have prepared fluorinated POPs (Figure 2, bottom right) by Pd-catalyzed $\mathrm{C}-\mathrm{H}$ activation of 1,2,4,5-tetrafluorobenzene and its subsequent coupling with trigonal and tetrahedral aryl bromides. ${ }^{46}$ Using ironporphyrin as a coupling partner, a series of fluorinated POPs was prepared with Brunauer-Emmett-Teller (BET) surface areas ranging between 670 and $840 \mathrm{~m}^{2} \mathrm{~g}^{-1} \cdot{ }^{47}$ These materials were shown to be competent heterogeneous catalysts for the Baeyer-Villiger oxidation of ketones, and the fluorinated groups were speculated to help in increasing the lifetime of the catalyst. Cooper and colleagues used a Sonogashira coupling of 1,3,5-triethynylbenzene with several extensively fluorinated aryl bromides to prepare POPs. ${ }^{48}$ In both Han's and Cooper's work, fluorination played a crucial role in the synthesis: the $\mathrm{C}-\mathrm{H}$ functionalization would not have proceeded on the nonfluorinated material, nor would aryl bromides be active enough in the Sonogashira coupling without fluorine substituents. In addition, fluorination influenced the properties of the prepared materials: they were found to be more hydrophobic than their nonfluorinated counterparts, and some showed high sorption capacities for electron-rich aromatics such as toluene. Variants of Cooper et al.'s alkyne-based fluorinated POPs have been shown to be excellent adsorbents for $\mathrm{CO}_{2}$ and $\mathrm{CH}_{4}$ (showing $\sim 100: 1$ and 8:1 selectivities over $\mathrm{N}_{2}$, respectively), ${ }^{49}$ as well as elemental iodine. ${ }^{50}$ Fluorinated POPs incorporating alkyne functional groups and phenanthroline moieties could coordinate $\mathrm{Ag}(\mathrm{I})$ and the resulting porous framework was capable of catalyzing the reaction of $\mathrm{CO}_{2}$ with propargyl alcohols. ${ }^{51}$ Very recently, Yavuz and coworkers have shown that alkyne-based perfluorinated POPs can be synthesized in the absence of transition metal catalysts. $^{52}$

Dichtel and coworkers have made a brilliant use of aromatic fluorine chemistry to prepare cyclodextrinbased POPs. ${ }^{53}$ Starting with the activated tetrafluoroterephthalonitrile 3 (Figure 3 ), an $\mathrm{S}_{\mathrm{N}} \mathrm{Ar}$ reaction with $\beta$ cyclodextrin (2) resulted in the replacement of 2.1-2.2 fluorines (on average) per molecule of $\mathbf{3}$ with the alkoxy groups of cyclodextrin, creating a porous polymer 4 (its structure in Figure 3 is simplified, as other connectivities are certainly possible). In it, rigid and hydrophobic fluoroarene and cyclodextrin moieties played a role in the creation of materials with surface areas as high as $263 \mathrm{~m}^{2} \mathrm{~g}^{-1}$, ${ }^{4}$ which could be used to remove nonpolar organic micropollutants from drinking water. These results were built on the previous work of Deng and coworkers who used fluorinated alkyne-based POPs to remove hydrophobic and heavy metal pollutants from water. ${ }^{55}$ Inclusion of cotton fibers during the polymerization creates materials that can capture volatile organic compounds from air. ${ }^{56}$ By using a related material derived from the reaction of $\beta$-cyclodextrin with decafluorobiphenyl, the same group showed efficient removal of the notoriously environmentally persistent perfluorooctanoic acid (PFOA, used as a surfactant and in the production of Teflon and fluorotelomers) ${ }^{57}$ In very recent work, they demonstrated that the reduction of the $-\mathrm{CN}$ group into $-\mathrm{CH}_{2} \mathrm{NH}_{2}$ dramatically enhances the affinity of the material for PFOA. ${ }^{58}$ Work on tailoring porous organic materials to capture water contaminants has recently been reviewed. ${ }^{59}$
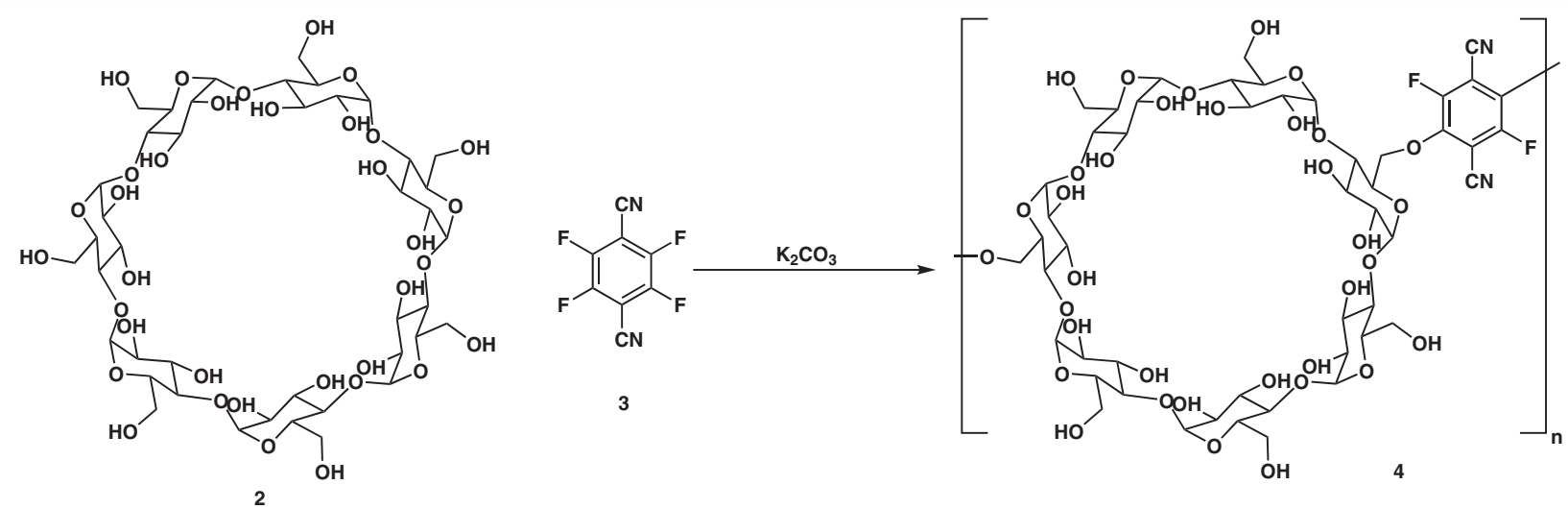

Figure 3 Polymerization of ß-cyclodextrin with tetrafluoroterephthalonitrile results in POPs which are capable of removing organic micropollutants from water. Polymerization product's structure is simplified. 


\section{Porous Molecular Crystals}

In 2015, our group made a serendipitous discovery. While attempting to prepare pyrazolate-based fluorinated ligands for MOFs-in the hope of enhancing their stability relative to their tetrazolate counterparts, mentioned earlier -we obtained single crystals of the organic starting material 5 (Figure 4, top left). This result would have normally been very disappointing. However, a more detailed analysis of the crystal structure revealed that the precursor pyrazole itself creates a porous structure (Figure 4, top right), held together by a combination of $[\mathrm{N}-\mathrm{H} \cdots \mathrm{N}]$ hydrogen bonds between terminal pyrazoles (Figure 4, bottom left) and aromatic $[\pi \cdots \pi]$ stacking interactions between electron-rich pyrazoles and electron-poor 1,2,4,5-tetrafluorobenzenes (Figure 4, bottom right). This framework proved to be remarkably robust in light of being stabilized only by noncovalent interactions: it did not decompose until $\sim 380^{\circ} \mathrm{C}$ and did not lose its structural integrity until $\sim 280^{\circ} \mathrm{C}$. At that temperature, our material transformed into another crystalline phase (as evidenced by variable temperature powder X-ray diffraction) which was not porous. This observation was in line with the demonstrated polymorphism of PMCs, which typically sees porous phases being kinetic products. ${ }^{60,61}$

In a subsequent exhaustive study, ${ }^{62}$ we have prepared a series of derivatives of $\mathbf{5}$, with the intention of identifying
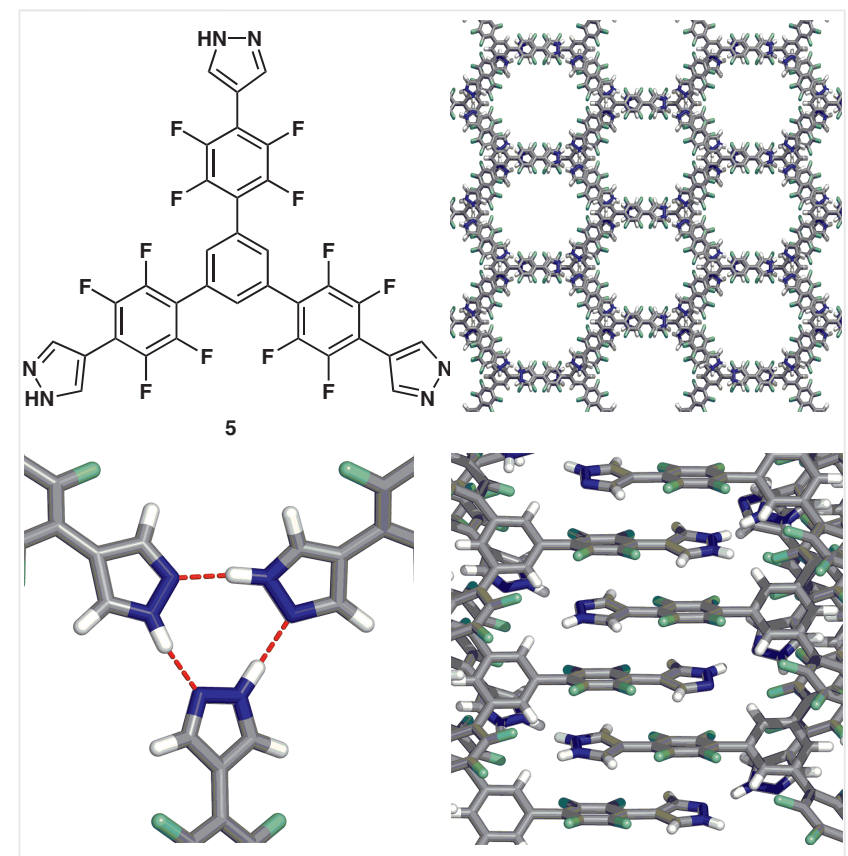

Figure 4 Fluorinated aromatic pyrazole 5 self-assembled into a porous structure (top right), through a combination of hydrogen bonds between terminal pyrazoles (bottom left) and $[\pi \cdots \pi]$ stacking between electron-rich pyrazoles and electron-poor tetrafluorobenzenes (bottom right). the molecular features necessary for the formation of the porous structure. The tetrafluorinated ring proved to be critical, as its replacement with a nonsubstituted benzene ring or a triple bond led to materials that could either not be crystallized or that crystallized in nonporous structures. This study identified three novel precursors to PMCs. They all shared certain structural features: trigonal structures, perfluorinated rings capable of aromatic stacking, and a hydrogen-bonding terminal group. Linear and bent precursors resulted in close-packed structures. In the solid state, $\mathbf{5}$ and $\mathbf{6}$ were isostructural (Figure 5, top); 7, as would be expected, had an expanded unit cell (Figure 5, bottom). Curiously, tetrazole 1-which is a precursor to the highly porous MOFF-5 (Figure 1)-also formed a porous solid-state structure on its own. The structure is different from those of 5-7, in which the coplanar triplets of hydrogen bonds were replaced with infinite one-dimensional (1D) chains of hydrogen-bonded tetrazoles (Figure 6, left), resulting in a more compact organization (Figure 6, right).

The most extensively investigated PMC in our group was based on compound $\mathbf{5}$. This material was found to be an excellent adsorbent for a variety of fluorinated specieswith capacities slightly lower than those observed for MOFF-5, but with vastly improved stability. Compound $\mathbf{5}$ was also a competent adsorbent for a number of fluorinated anesthetics. ${ }^{63}$ In addition, PMCs based on $\mathbf{5}$ proved to be piezochromic: upon guest entry into the pores, the pores would shrink in the hydrogen-bonding plane, but expand along the $[\pi \cdots \pi]$ stacking direction. ${ }^{64}$ This change, although small, was measurable and reproducible and constitutes a sensing mechanism for detecting guest entry into the pores.

PMCs can be dissolved in solvents such as DMF, which disrupts the hydrogen bonding between individual molecules. Their solubility allowed direct comparisons of optical properties in the solution and in the solid state. In the case of isostructural $\mathbf{5}$ and $\mathbf{6}$, solid-state absorption and fluorescence emissions were found to be virtually identical. However, upon dissolution, the two compounds behaved differently: $\mathbf{5}$ was fluorescent in dilute DMF solution, while 6 was not. ${ }^{65}$ With addition of water (which is a poor, aggregation-inducing solvent for both $\mathbf{5}$ and $\mathbf{6}$ ), the triazinecentered $\mathbf{6}$ exhibited aggregation-induced turning $\mathrm{ON}$ of emission (AIE effect), while the emission of 5 stayed more or less the same. This difference in emission properties was explained through the computational analysis of rotational barriers in $\mathbf{5}$ and $\mathbf{6}$. Because there are no hydrogen atoms on the central triazine ring of $\mathbf{6}$, rotation of the tetrafluorinated rings is relatively unrestricted; to become emissive, the intramolecular rotations of $\mathbf{6}$ have to be limited through water-induced aggregation. On the other hand, the fluorinated rings of $\mathbf{5}$ are not as flexible as those of $\mathbf{6}$ and thus remain in a close-to-emissive conformation regardless of the aggregation stage. We have further shown that this 
<smiles>Fc1c(F)c(-c2nc(-c3c(F)c(F)c(-c4cn[nH]c4)c(F)c3F)nc(-c3c(F)c(F)c(-c4cn[nH]c4)c(F)c3F)n2)c(F)c(F)c1-c1cn[nH]c1</smiles>
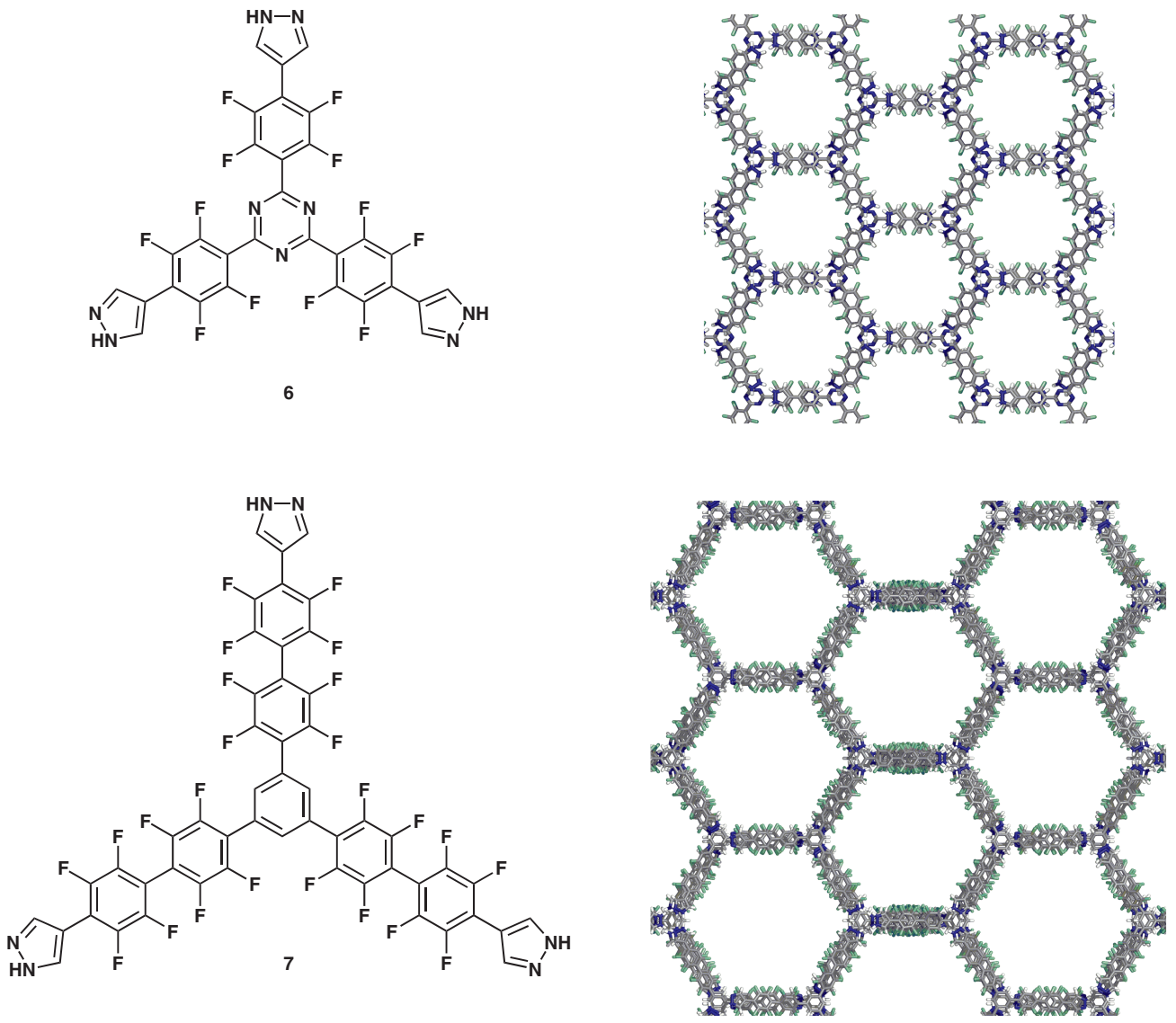

Figure $\mathbf{5}$ Trigonally shaped, fluorinated, and rigid trispyrazoles $\mathbf{6}$ and $\mathbf{7}$ self-assemble into porous structures isoreticular to that of $\mathbf{5}$ in the solid state.

switch of $\mathbf{6}$ from the freely rotating to the emissive conformation can be induced not only by aggregation, but also by supramolecular assembly. ${ }^{66}$ Namely, upon exposure to dicarboxylic acids with convergently positioned $-\mathrm{COOH}$ groups, such as 1,2-benzendicarboxylic acids or cis-alkenediacids, two molecules of $\mathbf{6}$ would come together into a dimer which restricts nonradiative decay (intramolecular rotations) and elicits emission. In a very recent work, we have examined a fluorinated tetragonal precursor to PMCs based on the central tetraphenylene ethylene unit, which is a well-documented AIEgen. ${ }^{67}$ This material shows switchable emission in the solid state, which can be toggled between green and blue by the removal and re-addition of the DMF solvent.
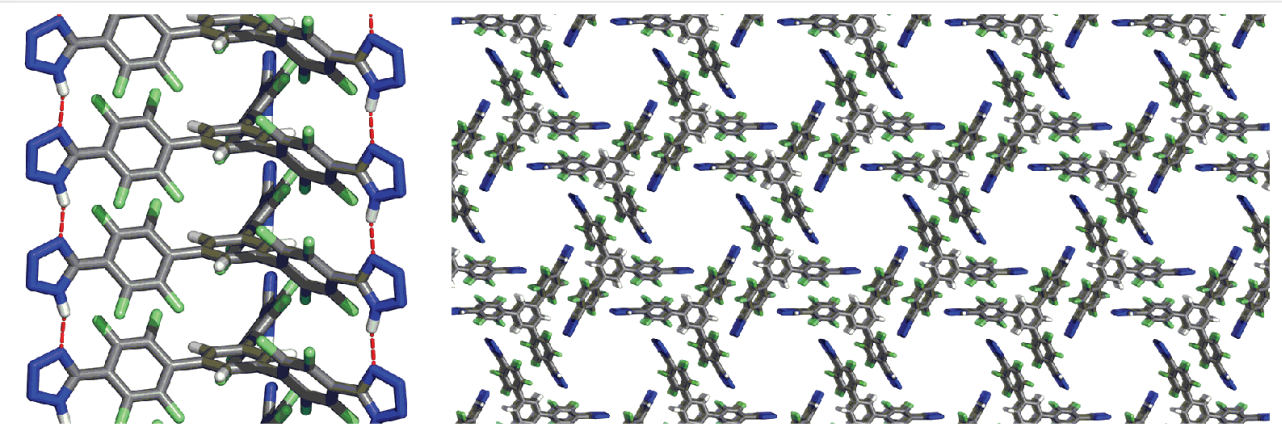

Figure 6 Crystal structure of 1 shows infinite 1D chains of hydrogen-bonded tetrazoles (left) and is porous, but more compact (right) than the structures of the closely related $\mathbf{5}$ and $\mathbf{6}$. 
Hisaki and coworkers have recently incorporated orthofluorine substituents into the structures of their porous hydrogen-bonded networks built on carboxylic acids. ${ }^{68}$ Relative to the nonfluorinated system, fluorination resulted in the loss of coplanarity between the benzene ring and the $\mathrm{COOH}$ group (common to the behavior of fluorinated MOFs) and significant rotational disordering of the $-\mathrm{COOH}$ groups.

Barbour and coworkers reported a porous halogenbonded framework, which was obtained by evaporating an acetone solution of 8 and $\mathbf{9}$ (Figure 7). ${ }^{69}$ The evaporation produced a solvated yellow porous molecular crystal, wherein I $\cdots \mathrm{N}$ interactions connect $\mathbf{8}$ and $\mathbf{9}$ in a sinusoidal infinite $(\mathbf{8} \cdots \mathbf{9} \cdots)_{n}$ chain. Adjacent chains interact with each other by weak $[\mathrm{C}-\mathrm{H} \cdots \mathrm{F}]$ contacts and $[\pi \cdots \pi]$ stacking between tetrafluorodiiodobenzenes and thiophenes, finally forming a porous structure with 1D guest-accessible channels. The weak intermolecular interactions allow the pores to change their shape and volume in response to guest molecules. For example, the voids are discrete when $\mathrm{CO}_{2}$ is introduced as the guest into the activated crystals of $\mathbf{8 . 9}$ but become 1D open channels when ethane is the guest. The volume per guest binding site changes from 55 to $143 \AA^{3}$. The I...N interactions almost do not change, but the $[\mathrm{C}-\mathrm{H} \cdots \mathrm{F}]$ interactions break during such structure expansion.

As we have seen in our work, the flexibility of fluorinated PMCs is also reflected in their fluorescence properties. Naka and coworkers prepared platinum dihalide complexes which crystallize in low-porosity structures with BET surface areas of 20 and $42 \mathrm{~m}^{2} \mathrm{~g}^{-1}$, respectively. ${ }^{70}$ Such PMCs are characterized by [C...F] short contacts between two fluorinated benzenes in edge-to-side mode and $[\pi \cdots \pi]$ stacking between the fluorinated and nonfluorinated aromatic rings. On account of their flexible structures, these PMCs can be transformed to nonporous crystals by exposure to $\mathrm{CH}_{2} \mathrm{Cl}_{2}$, which also results in the turning $\mathrm{ON}$ of

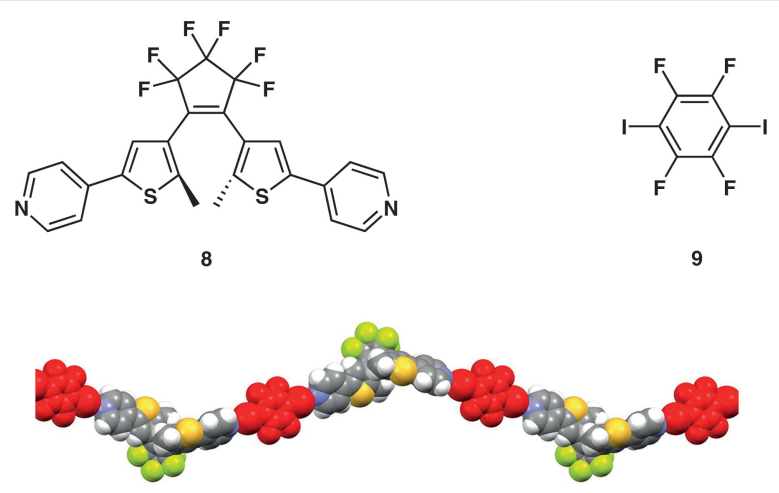

Figure $\mathbf{7}$ Co-crystallization of compounds 8 and $\mathbf{9}$ (top) results in a porous framework consisting of discrete 1D halogen-bonded chains (bottom, compound $\mathbf{9}$ shown in red). Flexible interactions between these chains allow their adjustment to various guests. red luminescence. Such change can be reversed by exposing the nonporous crystals to hexafluorobenzene.

Zhang and coworkers synthesized the single crystals of benzo-trisimidazole 10a (Figure 8 , top) by the solvothermal reaction of 1,3,5-triamino-2,4,6-trinitrobenzene, ${ }^{71}$ formic acid, and sodium formate at $160{ }^{\circ} \mathrm{C}$. In the solid state, each molecule of 10a is connected to three adjacent molecules by six $[\mathrm{N}-\mathrm{H} \cdots \mathrm{N}]$ bonds (Figure 8 , center), resulting in a twodimensional extended framework without significant porosity. ${ }^{72}$ After the removal of trapped $\mathrm{H}_{2} \mathrm{O}$, the activated crystals of 10a kept their original crystal structure, where the isolated cavities were blocked by two adjacent layers. Molecule 10b, functionalized with a $\mathrm{CF}_{3}$ group, formed a porous crystal with three-dimensional (3D) intersecting channels that had increased volume (36\%) and BET surface area $\left(131 \mathrm{~m}^{2} \mathrm{~g}^{-1}\right)$ compared to the parent molecule. The introduction of $\mathrm{CF}_{3}$ groups resulted in steric hindrance that twisted the adjacent molecules of $\mathbf{1 0 b}$ with respect to each other (Figure 8, bottom), opening up pores. The fluorinated material was capable of separating $\mathrm{O}_{2}$ from $\mathrm{Ar}$ and $\mathrm{N}_{2}$; the<smiles>[R]c1nc2c3nc(P)[nH]c3c3nc(P)[nH]c3c2[nH]1</smiles>
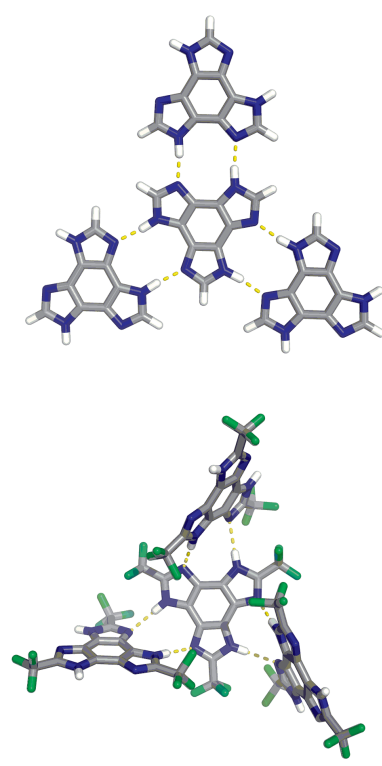

Figure 8 Benzo-trisimidazoles 10a and 10b (top) crystallize in very

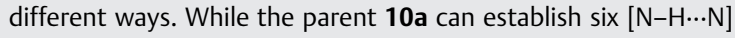
hydrogen bonds to its neighbors (center), the larger $10 \mathrm{~b}$ cannot because of its bulky $\mathrm{CF}_{3}$ group. Instead, it twists out of plane (bottom) and crystallizes in a porous structure. 
Organic Materials

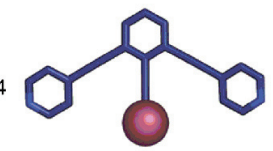<smiles>OCCOc1c(C#Cc2ccncc2)cccc1C#Cc1ccncc1</smiles>

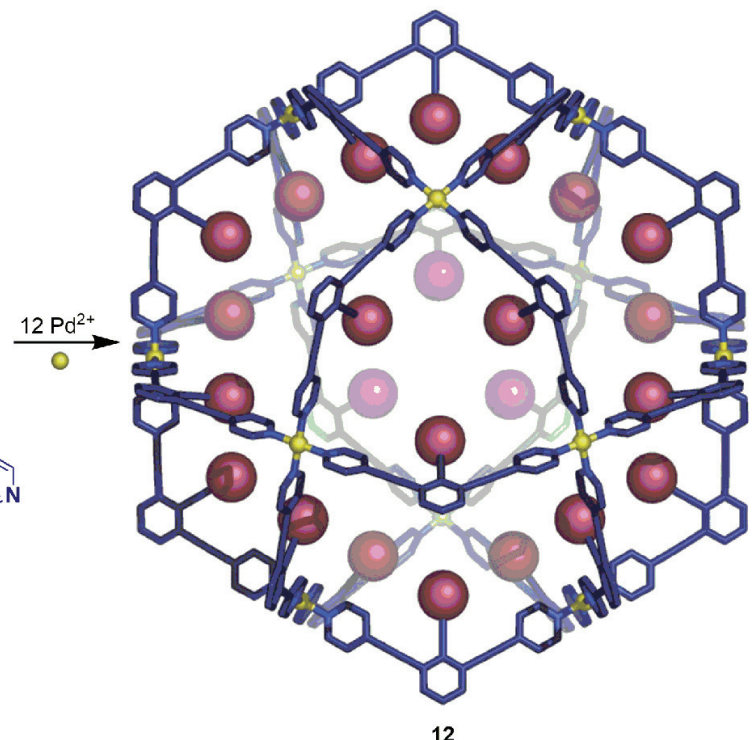

的, $\mathrm{R}_{\mathrm{F}}=\left(\mathrm{CF}_{2}\right)_{5} \mathrm{CF}_{3}$

$11 \mathrm{~b}, \mathrm{R}_{\mathrm{F}}=\left(\mathrm{CF}_{2}\right)_{7} \mathrm{CF}_{3}$

11c, $\mathrm{R}_{\mathrm{F}}=\left(\mathrm{CF}_{2}\right)_{6} \mathrm{CF}\left(\mathrm{CF}_{3}\right)_{2}$

$11 \mathrm{~d}, \mathrm{R}_{\mathrm{F}}=\left(\mathrm{CF}_{2}\right)_{3} \mathrm{CF}_{3}$

Figure 9 Synthesis of the internally fluorinated cages 12. (Reproduced with permission from Ref. 73.)

selectivity was attributed to its aperture size that resulted in only $\mathrm{O}_{2}$ being adsorbed effectively.

\section{Porous Fluorinated Cages}

In the construction of 3D molecular cages, fluorinated moieties can find themselves either on the inside (endofluorinated) or the outside (exofluorinated) of the cage. In 2006, Fujita and coworkers reported the synthesis of four endofluorinated molecular cages $\mathbf{1 2}$ by the reactions of bent-shaped dipyridines $\mathbf{1 1}$ and $\mathrm{Pd}\left(\mathrm{NO}_{3}\right)_{2}$ in DMSO- $d_{6}$ (Figure 9). ${ }^{73}$ The crystal structure of 12a reveals an ellipsoid-shaped cage, with dimension of $4.9 \times 4.2 \mathrm{~nm}$ and 24 perfluoroalkyl groups disordered as in a liquid state. Calculations indicated that there is a void at the very center of the cage, surrounded by the disordered and partially aggregated fluorinated groups that could not be crystallographically located. The solutions of 12a can selectively dissolve 5.8 molecules of perfluorooctane per capsule, and that number can be modulated by adjusting the length of the perfluoroalkyl groups in cages 12a-d.

The fluorination of starting materials can facilitate the porous materials' synthesis. Mastalerz and coworkers synthesized three shape-persistent tetrahedral boronic ester cages 15a-c (Figure 10) by the [4+6] condensation between nonfluorinated or fluorinated diboronic acids 13a-c and a brominated triptycene-based hexaol $\mathbf{1 4} .^{74}$ The fluorinated diboronic acids 13b and $\mathbf{1 3 c}$ have higher Lewis acidity than the nonfluorinated 13a, which reduced the reaction time

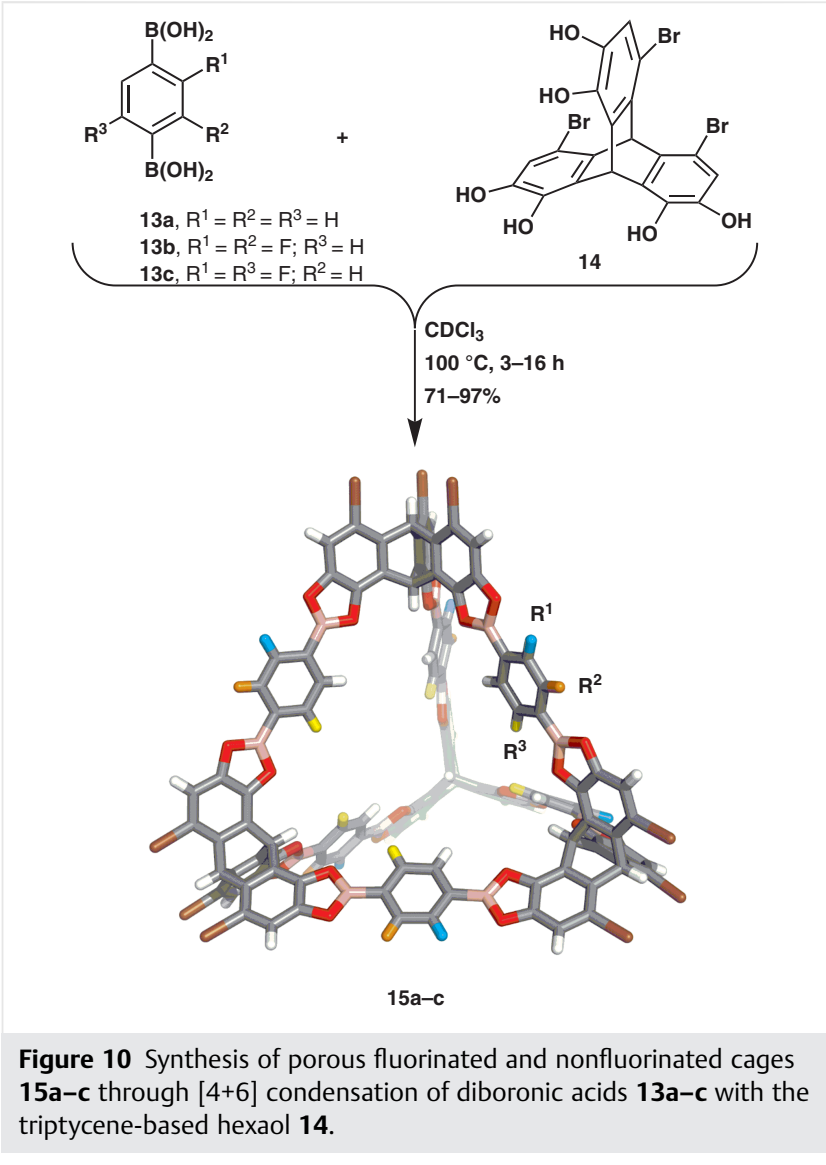


from $16 \mathrm{~h}$ to $3-4 \mathrm{~h}$. At the same time, the fluorinated cages are more susceptible to solvolysis in $\mathrm{MeOH}$, on account of the increased electrophilicity of the boron centers. Single crystals of 15a and 15b were obtained by slow vapor diffusion of $n$ pentane or $n$-hexane into $\mathrm{CDCl}_{3}$ solutions. The crystal structure of the nonfluorinated 15a features $[\pi \cdots \pi]$ stacking and short $\mathrm{B} \cdots \mathrm{Br}$ and $\mathrm{Br} \cdots \pi$ contacts. In the case of fluorinated $\mathbf{1 5 b},[\pi \cdots \pi]$ stacking is observed, along with apparent $[C-F \cdots \pi]$ and $[\mathrm{C}-\mathrm{F}$...B] interactions. Despite similar covalent radii of hydrogen and fluorine, fluorinated cages had dramatically lower BET surface areas of $69 \mathrm{~m}^{2} \mathrm{~g}^{-1}$ (15b) and $33 \mathrm{~m}^{2} \mathrm{~g}^{-1}$ (15c) compared with the nonfluorinated 15a $\left(577 \mathrm{~m}^{2} \mathrm{~g}^{-1}\right)$.

Cooper and coworkers performed a side-by-side comparison of the fluorinated and nonfluorinated imine-based cages. ${ }^{75}$ Using a [4+6] cycloimination of 1,3,5-triformylbenzene (16, Figure 11) with $(R, R)$-1,2-diphenylethylenediamine (17a) and $(R, R)$-1,2-bis(4-fluorophenyl)ethane-1,2-diamine (17b), they synthesized two novel imine cages 18a $(R=H)$ and $18 \mathbf{b}(\mathrm{R}=\mathrm{F})$. The intention behind this study was to test whether the bulky aryl groups at the cages' vertices would frustrate the efficient packing and lead to increased porosity (as well as to probe the influence of fluorination). Cage 18a was found to crystallize in two major forms, which belonged

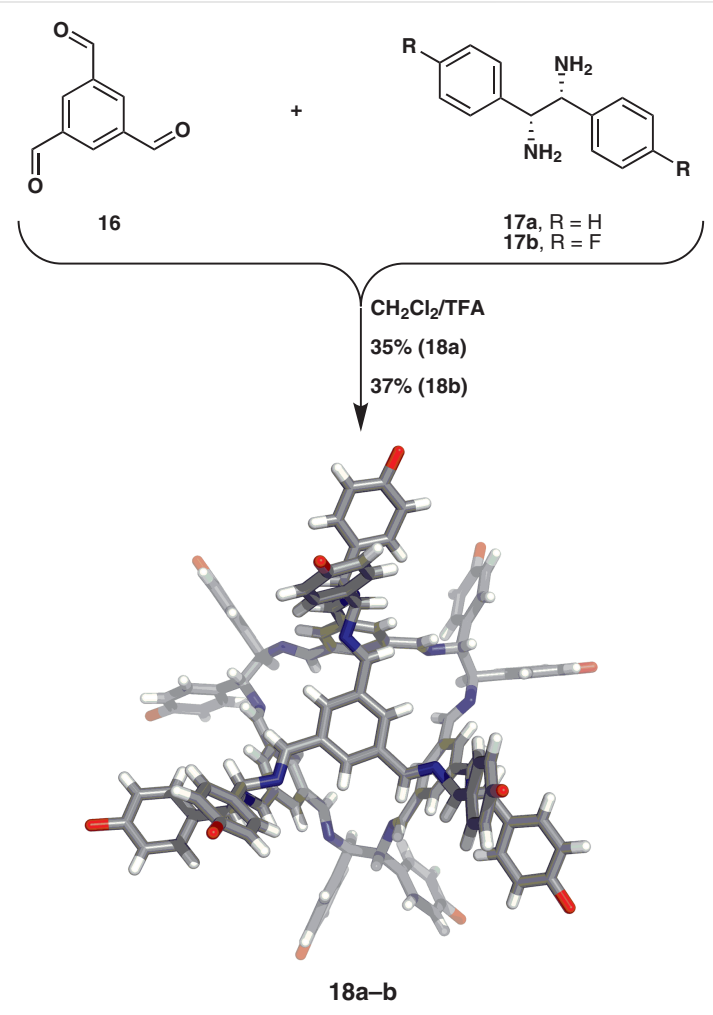

Figure 11 Synthesis of porous fluorinated and nonfluorinated imine cages 18a-b through [4+6] condensation of trialdehyde 16 with diamines $17 \mathbf{a}$ and $\mathbf{1 7 b}$. to space groups $P 3$ (prior to desolvation) and $R 3$ (after desolvation), while 18b quickly desolvated to a structure in the $R 32$ space group. A face-to-window stacking along the crystallographic $c$-axis was observed for both polymorphs of $18 \mathbf{a}(P 3$ and $R 3)$. The major difference between the two crystal forms is that the intrinsic pores connect to adjacent extrinsic pores in 18a $(P 3)$, but not in 18a $(R 3)$. Neither of the crystal forms shows significant short contacts $(<2.5 \AA$, electrostatic interactions or hydrogen bonding) among the cages. For a desolvated crystal of fluorinated $\mathbf{1 8 b}(R 32)$, each molecule of $\mathbf{1 8 b}$ packs alternately in window-to-window and face-to-face with the two adjacent molecules of $\mathbf{1 8 b}$ along the crystallographic $c$-axis. Such different packing modes between 18a and $\mathbf{1 8 b}$ are due to the introduction of fluorinated aromatic rings, which engage in $[\mathrm{C}-\mathrm{H} \cdot \ldots \mathrm{F}]$ hydrogen bonding and quadrupole-complementary $[\pi \cdots \pi]$ stacking. The overall result is a more rigid structure, in which extrinsic channels are sealed. This anisotropic ordering on account of fluorination may be the reason why other polymorphs of $\mathbf{1 8 b}$ have not been identified. The tested BET surface area of the fluorinated $\mathbf{1 8 b}\left(533 \mathrm{~m}^{2} \mathrm{~g}^{-1}\right)$ is comparable to that of $18 \mathbf{a}-R 3\left(575 \mathrm{~m}^{2} \mathrm{~g}^{-1}\right)$, but almost twice lower than that of 18a in the $P 3$ space group $\left(952 \mathrm{~m}^{2} \mathrm{~g}^{-1}\right)$.

\section{Conclusions and Outlook}

The golden age of fluorine continues in the field of porous materials too. While the number of studies explicitly focused on fluorinated porous materials remains relatively moderate, some effects can already be identified. First, fluorination frequently plays a nontrivial role in the synthesis of the precursors to porous materials, allowing access to $\mathrm{C}-\mathrm{H}$ and deprotonation-based methodologies that are often unavailable for the nonfluorinated counterparts. Second, extensively fluorinated aromatic rings routinely engage in $[\pi \cdots \pi]$ stacking, which can be either a structural feature-facilitating the solid-state organization of the porous material-or a functional asset-operational in the binding of electron-rich aromatic guests. Other fluorinated groups, such as trifluoromethyl, are sterically significantly bulkier and occasionally end up filling the pores. Third, the high electronegativity of fluorine atoms means that they repel neighboring groups, frequently resulting in the deplanarization; this feature is the reason behind the limited ability to prepare fluorinated MOFs isostructural to their nonfluorinated counterparts. Finally, fluorination affects the thermal stability of the prepared materials, although not always in the same fashion. While C-F bonds, especially in the aromatic systems, tend to be stronger than $\mathrm{C}-\mathrm{H}$ bonds, fluorination tends to weaken the bonds to neighboring groups. Thus, decarboxylation of fluorinecontaining MOFs is often easier, and thus their stability lower than in the nonfluorinated systems. 
What challenges remain? More synthetic work is needed to expand the range of available materials and structures. Among the currently available materials, fluoroarene building blocks have been explored, but much less attention has been paid to the fluorinated alkyl chains. Sideby-side comparisons between fluorinated and nonfluorinated materials are needed. Finally, chemical reactivity of fluorinated species within porous materials has been underexplored, with the exception of Dichtel and coworkers' work on cyclodextrin-containing POPs. This omission is unfortunate, as postsynthetic modification of fluorinated materials could be used to tune their level of fluorination (and the associated hydrophobicity) or to introduce functional groups that otherwise could not have been directly incorporated. ${ }^{76}$ Our group is exploring these directions and will report the results in due course.

\section{Acknowledgement}

Over the years, the work in our labs has been supported by the University of Houston, the National Science Foundation (DMR-1507664 and DMR-1904998), the Welch Foundation (E-1768), and the donors of the American Chemical Society Petroleum Research Fund (58919-ND4). Ognjen Š. Miljanić is a Cottrell Scholar of the Research Corporation for Science Advancement. Parts of this manuscript have been written at the Ruprecht-Karls-Universität in Heidelberg and the Alexander von Humboldt Foundation is acknowledged for supporting Ognjen Š. Miljanić's stay there.

\section{References}

(1) CRC Handbook of Chemistry and Physics, 100th ed. Rumble, J. CRC Press: Boca Raton, 2019.

(2) Wang, J.; Sánchez-Roselló, M.; Aceña, J. L.; del Pozo, C.; Sorochinsky, A. E.; Fustero, S.; Soloshonok, V. A.; Liu, H. Chem. Rev. 2014, 114, 2432-2506.

(3) Tomashenko, O. A.; Grushin, V. V. Chem. Rev. 2011, 111, 4475-4521.

(4) Shimizu, M.; Hiyama, T. Angew. Chem. Int. Ed. 2004, 44, 214-231.

(5) Fluorinated Materials for Energy Conversion. Nakajima, T.; Groult, H. Elsevier: Amsterdam, 2005.

(6) Ragni, R.; Punzi, A.; Babudri, F.; Farinola, G. M. Eur. J. Org. Chem. 2018, 3500-3519.

(7) Pachfule, P.; Banerjee, R. Fluorinated Metal-Organic Frameworks (FMOFs): Concept, Construction, and Properties, Encyclopedia of Inorganic and Bioinorganic Chemistry. MacGillivray, L. R.; Lukehart, C. M. John Wiley \& Sons: Chichester, 2014, 85-98.

(8) Noro, S.; Nakamura, T. NPG Asia Mater. 2017, 9, e433.

(9) Metal-Organic Frameworks: Applications in Separations and Catalysis. García, H.; Navalón, S. Wiley-VCH: Weinheim, 2018.

(10) The Chemistry of Metal-Organic Frameworks: Synthesis, Characterization, and Applications. Kaskel, S. Wiley-VCH: Weinheim, 2016.

(11) Metal-Organic Frameworks: Applications from Catalysis to Gas Storage. Farrusseng, D. Wiley-VCH: Weinheim, 2011.
(12) Metal-Organic Frameworks: Design and Application. MacGillivray, L. R. Wiley: Hoboken, 2010.

(13) Kandambeth, S.; Dey, K.; Banerjee, R.J. Am. Chem. Soc. 2019, 141, 1807-1822.

(14) Huang, N.; Wang, P.; Jiang, D. Nat. Rev. Mater. 2016, 1, 16068.

(15) Feng, X.; Ding, X.; Jiang, D. Chem. Soc. Rev. 2012, 41, 6010-6022.

(16) Zhao, W.; Xia, L.; Liu, X. Cryst. Eng. Comm. 2018, 20, 1613-1634.

(17) Hisaki, I.; Xin, C.; Takahashi, K.; Nakamura, T. Angew. Chem. Int. Ed. 2019, 58, 11160-11170.

(18) Hashim, M. I.; Hsu, C. W.; Le, H. T. M.; Miljanić, O. Š. Synlett 2016, 27, 1907-1918.

(19) Cooper, A. I. ACS Cent. Sci. 2017, 3, 544-553.

(20) Evans, J. D.; Sumby, C. J.; Doonan, C. J. Chem. Lett. 2015, 44, 582-588.

(21) Zhang, G.; Mastalerz, M. Chem. Soc. Rev. 2014, 43, 1934-1947.

(22) Holst, J. R.; Trewin, A.; Cooper, A. I. Nat. Chem. 2010, 2, 915-920.

(23) Yang, C.; Wang, X.; Omary, M. A. J. Am. Chem. Soc. 2007, 129, 15454-15455.

(24) Pachfule, P.; Dey, C.; Panda, T.; Vanka, K.; Banerjee, R. Cryst. Growth Des. 2010, 10, 1351-1363.

(25) Yang, C.; Kaipa, U.; Mather, Q. Z.; Wang, X.; Nesterov, V.; Venero, A. F.; Omary, M. A. J. Am. Chem. Soc. 2011, 133, 18094-18097.

(26) Nijem, N.; Canepa, P.; Kaipa, U.; Tan, K.; Roodenko, K.; Tekarli, S. M.; Halbert, J.; Oswald, I. W. H.; Arvapally, R. K.; Yang, C.; Thonhauser, T.; Omary, M. A.; Chabal, Y. J.J. Am. Chem. Soc. 2013, 135, 12615-12626.

(27) Chen, T. H.; Popov, I.; Zenasni, O.; Daugulis, O.; Miljanić, O. Š. Chem. Commun. 2013, 49, 6846-6848.

(28) Chen, T. H.; Popov, I.; Kaveevivitchai, W.; Chuang, Y. C.; Chen, Y. S.; Jacobson, A. J.; Miljanić, O. Š. Angew. Chem. Int. Ed. 2015, 54, 13902-13906.

(29) Motkuri, R. K.; Annapureddy, H. V. R.; Vijaykumar, M.; Schaef, H. T.; Martin, P. F.; McGrail, B. P.; Dang, L. X.; Krishna, R.; Thallapally, P. K. Nat. Commun. 2014, 5, 4368.

(30) Gao, C.; Li, J.; Yin, S.; Lin, G.; Ma, T.; Meng, Y.; Sun, J.; Wang, C. Angew. Chem. Int. Ed. 2019, 58, 9770-9775.

(31) Braunecker, W. A.; Hurst, K. E.; Ray, K. G.; Owczarczyk, Z. R.; Martines, M. B.; Leick, N.; Keuhlen, A.; Sellinger, A.; Johnson, J. C. Cryst. Growth Des. 2018, 18, 4160-4166.

(32) Chen, X.; Addicoat, M.; Irle, S.; Nagai, A.; Jiang, D. J. Am. Chem. Soc. 2013, 135, 546-549.

(33) Alahakoon, S. B.; McCandless, G. T.; Karunathilake, A. A. K.; Thompson, C. M.; Smaldone, R. A. Chem. Eur. J. 2017, 23, 4255-4259.

(34) Alahakoon, S. B.; Occhialini, G.; McCandless, G. T.; Karunathilake, A. A. K.; Nielsen, S. O.; Smaldone, R. A. Cryst. Eng. Comm. 2017, 19, 4882-4885.

(35) For a recent review of CTFs, see: Liu, M.; Guo, L.; Jin, S.; Tan, B. J. Mater. Chem. A 2019, 7, 5153-5172.

(36) Wang, Y.; Chen, J.; Wang, G.; Li, Y.; Wen, Z. Angew. Chem. Int. Ed. 2018, 57, 13120-13124.

(37) Je, S. H.; Kim, H. J.; Kim, J.; Choi, J. W.; Coskun, A. Adv. Funct. Mater. 2017, 27, 1703947.

(38) Xu, F.; Yang, S.; Jiang, G.; Ye, Q.; Wei, B.; Wang, H. ACS Appl. Mater. Interfaces 2017, 9, 37731-37738.

(39) Wang, D. G.; Li, N.; Hu, Y.; Wan, S.; Song, M.; Yu, G.; Jin, Y.; Wei, W.; Han, K.; Kuang, G. C.; Zhang, W. ACS Appl. Mater. Interfaces 2018, 10, 42233-42240.

(40) Zhao, Y.; Yao, K. X.; Teng, B.; Zhang, T.; Han, Y. Energy Environ. Sci. 2013, 6, 3684-3692.

(41) Dey, S.; Bhunia, A.; Breitzke, H.; Groszewicz, P. B.; Buntkowsky, G.; Janiak, C. J. Mater. Chem. A 2017, 5, 3609-3620. 
(42) Wang, G.; Leus, K.; Jena, H. S.; Krishnaraj, C.; Zhao, S.; Depauw, H.; Tahir, N.; Liu, Y. Y.; van der Voort, P. J. Mater. Chem. A 2018, 6, 6370-6375.

(43) Yang, Z.; Wang, S.; Zhang, Z.; Guo, W.; Jie, K.; Hashim, M. I.; Miljanić, O. Š.; Jiang, D.-e.; Popovs, I.; Dai, S. J. Mater. Chem. A 2019, 7, 17277-17282.

(44) Wang, S.; Tian, Z.; Dai, S.; Jiang, D. e. J. Phys. Chem. C 2017, 121, 22025-22030.

(45) Mukherjee, S.; Zeng, Z.; Shirolkar, M. M.; Samanta, P.; Chaudhari, A. K.; Tan, J. C.; Ghosh, S. K. Chem. Eur. J. 2018, 24, 11771-11778.

(46) Liu, D.; Chen, Q.; Zhao, Y.; Zhang, L.; Qi, A. D.; Han, B. H. ACS Macro Lett. 2013, 2, 522-526.

(47) Cao, Q.; Yin, Q.; Chen, Q.; Dong, Z. B.; Han, B. H. Chem. Eur.J. 2017, 23, 9831-9837.

(48) Dawson, R.; Laybourn, A.; Clowes, R.; Khimyak, Y.Z.; Adams, D. J.; Cooper, A. I. Macromolecules 2009, 42, 8809-8816.

(49) Comotti, A.; Castiglioni, F.; Bracco, S.; Perego, J.; Pedrini, A.; Negroni, M.; Sozzani, P. Chem. Commun. 2019, 55, 8999-9002.

(50) Li, G.; Yao, C.; Wang, J.; Xu, Y. Sci. Rep. 2017, 7, 13972.

(51) Yang, Z. Z.; Zhao, Y.; Zhang, H.; Yu, B.; Ma, Z.; Ji, G.; Liu, Z. Chem. Commun. 2014, 50, 13910-13913.

(52) Kim, S.; Thirion, D.; Nguyen, T. S.; Kim, B.; Dogan, N. A.; Yavuz, C. T. Chem. Mater. 2019, 31, 5206-5213.

(53) Alsbaiee, A.; Smith, B. J.; Xiao, L.; Ling, Y.; Helbling, D. E.; Dichtel, W. R. Nature 2016, 529, 190-194.

(54) Surface area of the prepared material varied in the range between 35 and $263 \mathrm{~m}^{2} \mathrm{~g}^{-1}$, depending on the ratio of the two precursors used in the polymerization.

(55) Yang, R. X.; Wang, T. T.; Deng, W. Q. Sci. Rep. 2015, 5, 10155.

(56) Alzate-Sánchez, D. M.; Smith, B. J.; Alsbaiee, A.; Hinestroza, J. P.; Dichtel, W. R. Chem. Mater. 2016, 28, 8340-8346.

(57) Xiao, L.; Ling, Y.; Alsbaiee, A.; Li, C.; Helbling, D. E.; Dichtel, W. R. J. Am. Chem. Soc. 2017, 139, 7689-7692.

(58) Klemes, M. J.; Ling, Y.; Ching, C.; Wu, C.; Xiao, L.; Helbling, D. E.; Dichtel, W. R. Angew. Chem. Int. Ed. 2019, 58, 12049-12053.

(59) Fernandes, S. P. S.; Romero, V.; Espiña, B.; Salonen, L. M. Chem. Eur. J. 2019, 25, 6461-6473.

(60) Pulido, A.; Chen, L.; Kaczorowski, T.; Holden, D.; Little, M. A.; Chong, S. Y.; Slater, B. J.; McMahon, D. P.; Bonillo, B.; Stackhouse,
C. J.; Stephenson, A.; Kane, C. M.; Clowes, R.; Hasell, T.; Cooper, A. I.; Day, G. M. Nature 2017, 543, 657-664.

(61) Kohl, B.; Rominger, F.; Mastalerz, M. Chem. Eur. J. 2015, 21, 17308-17313.

(62) Hashim, M. I.; Le, H. T. M.; Chen, T. H.; Chen, Y. S.; Daugulis, O.; Hsu, C. W.; Jacobson, A. J.; Kaveevivitchai, W.; Liang, X.; Makarenko, T.; Miljanić, O. Š.; Popovs, I.; Tran, H. V.; Wang, X.; Wu, C. H.; Wu, J. I. J. Am. Chem. Soc. 2018, 140, 6014-6026.

(63) Chen, T. H.; Kaveevivitchai, W.; Jacobson, A. J.; Miljanić, O. Š. Chem. Commun. 2015, 51, 14096-14098.

(64) Hendon, C. H.; Wittering, K. E.; Chen, T. H.; Kaveevivitchai, W.; Popov, I.; Butler, K. T.; Wilson, C. C.; Cruickshank, D. L.; Miljanić, O. Š.; Walsh, A. Nano Lett. 2015, 15, 2149-2154.

(65) Zhang, Z.; Hashim, M. I.; Miljanić, O. Š. Chem. Commun. 2017, 53, 10022-10025.

(66) Zhang, Z.; Hashim, M. I.; Wu, C. H.; Wu, J. I.; Miljanić, O. Š. Chem. Commun. 2018, 54, 11578-11581.

(67) Zhang, Z.; Lieu, T.; Wu, C. H.; Wang, X.; Wu, J. I.; Daugulis, O.; Miljanić, O. Š. Chem. Commun. 2019, 55, 9387-9390.

(68) Hisaki, I.; Ikenaka, N.; Tsuzuki, S.; Tohnai, N. Mater. Chem. Front. 2018, 2, 338-346.

(69) Nikolayenko, V. I.; Castell, D. C.; van Heerden, D. P.; Barbour, L. J. Angew. Chem. Int. Ed. 2018, 57, 12086-12091.

(70) Sasaki, H.; Imoto, H.; Kitao, T.; Uemura, T.; Yumura, T.; Naka, K. Chem. Commun. 2019, 55, 6487-6490.

(71) Mahmood, J.; Kim, D.; Jeon, I. Y.; Lah, M. S.; Baek, J. B. Synlett 2013, 24, 246-248.

(72) Zhou, D. D.; Xu, Y. T.; Lin, R. B.; Mo, Z. W.; Zhang, W. X.; Zhang, J. P. Chem. Commun. 2016, 52, 4991-4994.

(73) Sato, S.; Iida, J.; Suzuki, K.; Kawano, M.; Ozeki, T.; Fujita, M. Science 2006, 313, 1273-1276.

(74) Elbert, S. M.; Regenauer, N. I.; Schindler, D.; Zhang, W. S.; Rominger, F.; Schröder, R. R.; Mastalerz, M. Chem. Eur.J. 2018, 24, 11438-11443.

(75) Bojdys, M. J.; Briggs, M. E.; Jones, J. T. A.; Adams, D. J.; Chong, S. Y.; Schmidtmann, M.; Cooper, A. I. J. Am. Chem. Soc. 2011, 133, 16566-16571.

(76) Ong, W. J.; Swager, T. M. Nat. Chem. 2018, 10, 1023-1030. 